Research Article

\title{
The Innovative Design of Deep In Situ Pressure Retained Coring Based on Magnetic Field Trigger Controller
}

\author{
Guikang Liu $\mathbb{D},{ }^{1,2}$ Mingzhong Gao $\mathbb{D},{ }^{1,2}$ Zhiwen Yang, ${ }^{3}$ Ling Chen, ${ }^{4}$ Maoquan Fu, ${ }^{3}$ \\ and Heping Xie ${ }^{1,2}$ \\ ${ }^{1}$ State Key Laboratory of Hydraulics and Mountain River Engineering, College of Water Resource and Hydropower, \\ Sichuan University, Chengdu 610065, China \\ ${ }^{2}$ Guangdong Provincial Key Laboratory of Deep Earth Sciences and Geothermal Energy Exploitation and Utilization, \\ Institute of Deep Earth Sciences and Green Energy, College of Civil and Transportation Engineering, Shenzhen University, \\ Shenzhen 518060, China \\ ${ }^{3}$ Technology Center, Datong Coal Mine Group Corporation Limited, Datong 037003, China \\ ${ }^{4}$ School of Mechanical Engineering, Sichuan University, Chengdu 610065, China
}

Correspondence should be addressed to Mingzhong Gao; gmzh@scu.edu.cn

Received 8 August 2020; Revised 20 August 2020; Accepted 28 August 2020; Published 8 September 2020

Academic Editor: Fengqiang Gong

Copyright $\odot 2020$ Guikang Liu et al. This is an open access article distributed under the Creative Commons Attribution License, which permits unrestricted use, distribution, and reproduction in any medium, provided the original work is properly cited.

Deep rock mass theory has not yet been completely established, which leads to a lack of theoretical guidance for deep resource development and poor continuity among engineering activities. The foundation of deep rock mechanics theory is to achieve the deep in situ rock fidelity coring (including the retaining of the pore pressure and temperature). To realize this, pressure-retaining coring technology is required. A self-triggered pressure-retaining controller based on magnetic control is proposed in this paper. The pressure-retaining controller realizes pressure-retaining coring in any direction by triggering the closure of the valve cover by a magnetic force, forming a magnetic seal. Fifteen combined magnetic circuit design schemes are proposed. The magnetic flux density norm distribution and magnetic force evolution law of different schemes are then quantitatively analyzed by the finite element method. The results show that a complex magnetization combination can weaken the nonlinear negative correlation between the magnetic force and distance. The optimal design of the valve seat magnetic circuit is Scheme 9, with the valve seat consisting of four shape identical tile magnets. Among the schemes, for Scheme 9, the magnetic flux density norm of the valve cover is the most concentrated. The maximum magnetic flux density norm is in the middle, and the magnetic force at $35 \mathrm{~mm}$ from the valve cover to the valve seat is $2.915 \mathrm{~N}$. Scheme 9 satisfies the minimum condition of the mechanical model and verifies the feasibility of magnetic field triggering. This research can be used to gain a better understanding of deep Earth properties and provides technology for the improved design of deep in situ pressure-retaining coring devices.

\section{Introduction}

At present, deep rock mass engineering activities are far ahead of basic theoretical research, but deep rock mass mechanics theory has not been fully established, leading to a certain degree of unawareness, inefficiency, and uncertainty in deep resource development engineering activities [1]. For example, the study on spalling failure of deep tunnel surrounding rocks, the relationship between the strength of mine surrounding rocks and abutment pressure, the control of deep gas, the destructive study of rock burst, etc. all require the support of deep rock mechanics theory [2-4]. Therefore, it is urgent to systematically study deep rock mechanics theory and form the corresponding deep mining theory. The key to studying deep rock mechanics theory and methods is to realize deep in situ high-fidelity coring $[1,5]$. Xie et al. [6] first proposed in situ high-fidelity deep rock coring technology (including the retaining of the original pore pressure, temperature, quality, luminosity, and humidity of cores) based on the urgency of the development of deep rock mechanics theory. They explained the importance of pressure-preserving coring. In addition, they indicated 
that the principle and technology of pressure-retaining coring, which directly determines the accuracy of the pressure-retaining ability and influences the effect of heat preservation, quality preservation, luminosity preservation, and humidity preservation, is the key to deep in situ highfidelity coring. Pressure-retaining coring technology is an advanced and technically difficult drilling coring technology that adopts advanced pressure-retaining and closed coring tools. This technology can remove deep in situ cores that maintain or nearly maintain the original stress and are not contaminated by the drilling fluid. This technology is of great significance to obtain accurate deep rock data $[7,8]$. Presently, pressure-retaining coring technology is used in petroleum exploration and development, natural gas and deepwater gas hydrate exploration, deep coalbed gas exploration and development, marine deep resource exploration, and deep geological exploration [9-16]. Pressure-retaining coring is of great economic and strategic significance for resource development and exploration [17]. The key to the pressure-retaining coring technique is the pressure-retaining coring device. Among such devices, the pressure core barrel (PCB) has been used in the international Deep Sea Drilling Project (DSDP) [18], the advanced piston corer (APC) and pressure core sampler (PCS) have been used in the Ocean Drilling Program (ODP) $[19,20]$, the Fugro pressure corer (FPC) and Hydrate Autoclave Coring Equipment (HYACE) rotary corer (HRC) have been applied $[21,22]$, and the multiple autoclave corer (MAC) and dynamic autoclave piston corer (DAP) have been used for coring during the "RV SONNE" cruise $[23,24]$. In addition, pressure core extractors include the pressure-temperature core sampler (PTCS) developed in Japan [25], the gravity piston-type gas hydrate high-fidelity coring device developed in China [26], the natural gas hydrate (NGH) deepwater shallow-hole insulated and pressure-retaining core drilling tool developed by the First Institute of Oceanography [27], and the pressure and temperature preservation system (PTPS) for NGHs developed by Zhu et al. [28]. In recent years, China's pressure-retaining coring technology has also made great progress, gradually forming two major technical categories: offshore wire line pressure-retaining coring technology and onshore drilling type pressureretaining coring technology [29].

Currently, the pressure-maintaining sealing devices of pressure-retaining coring tools commonly used worldwide include ball valves [30,31], flap valves [32, 33], and ice valves [34,35]. Xie et al. [6] innovated and developed a selftriggered pressure-retaining control technology for deep in situ coring based on the geometry of a square cover, providing a new principle, technology, and test platform for exploring the difference in the in situ physical and mechanical properties of rock at different occurrence depths. At the same time, this technique can be used to solve the theoretical and technical problems of deep resource mining and to construct a research system of deep rock mechanics and mining theory [36]. He et al. [37] analyzed several schemes of the square cover and optimized the pressure retention ability of the square cover. The essence of the square cover is the flap valve structure, and its working principle is as follows. A trigger shrapnel is provided on the back of the flap valve cover. When the coring is completed, due to the lifting of the inner barrel of the coring chamber, the shrapnel starts the valve cover. Under the action of the cover's own gravity, it reverses to the matching valve seat at the bottom of the pressure-holding barrel to complete the automatic sealing [6].

In the exploitation of deep coal resources, geologic bedding is often present in the rock body, and the coal seam usually contains some precursory fractures [38]. Therefore, the excavation of mine roadways will lead to the destruction of the surrounding rock and other factors, resulting in the reduction in gas pressure [39]. When the surrounding rock is destroyed, the study of the dynamic failure mechanism of coal and gas outbursts will be more complicated [3]. In addition, the construction of deep underground engineering will cause abnormal energy storage and dissipation in the deep rocks $[5,40]$. A pressure-retaining tool can be used to obtain a pressure-retaining core in all directions from the roadway space and thus will be helpful to carry out more extensive and more accurate in situ scientific research in deep rock. However, the application range of the pressureretaining controller is limited by the deadweight closure of the valve cover, which is difficult to apply in some special pressure-retaining coring fields. We propose the design of a pressure-retaining coring device that can work in any direction. The magnetic field is an important form of energy that has been used continuously by engineers for hundreds of years for exploration [41]. Therefore, an innovative pressure-retaining controller based on a magnetic field trigger is designed in this paper so that the valve cover is no longer subject to gravity. Such a device can be used for pressure-retaining coring of a target formation in any direction in coal mines, shale gas fields, and other fields. This device provides in situ cores for the study of coal seam gas distribution, deep rock burst tendency, and destructive evaluation $[42,43]$. The feasibility of this innovative design is verified through the preliminary exploration of the magnetic field space, and the optimal magnetic circuit design is obtained, which provides data support and a theoretical basis for the study of the magnetic field self-triggered pressureretaining controller.

\section{Magnetic Field Control Mechanical Model of the Pressure-Retaining Controller}

2.1. How Magnetic Field Control Works? With the limited design space available due to the accommodation of the mechanical structure of the coring drill, the use of a magnetic force instead of gravity is proposed to realize the selftriggered closure of the valve cover in any direction under the constraint of a nonmechanical structure, as shown in Figure 1. A magnetic force has many advantages, such as easy control, energy savings, pollution reduction, and simple structure, and it is widely used in machinery [44]. A cylindrical groove outside the valve seat is cut, and the permanent magnet is inserted on the outside of the valve seat to form a permanent magnet valve seat, as shown in Figure 2. The magnetic force generated by the magnetic field of the 


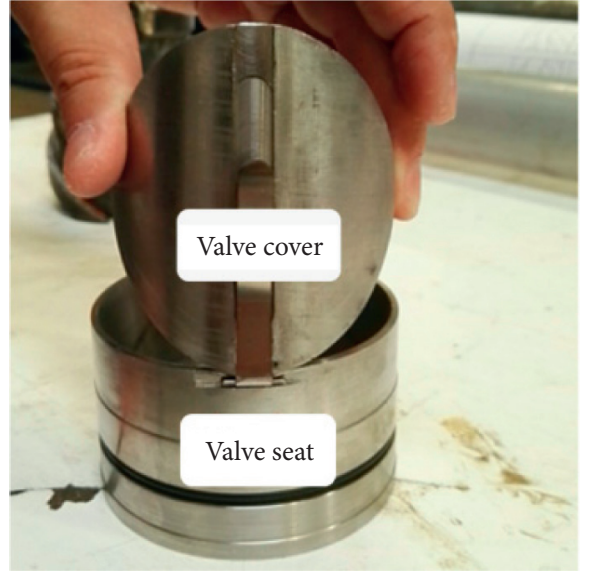

(a)

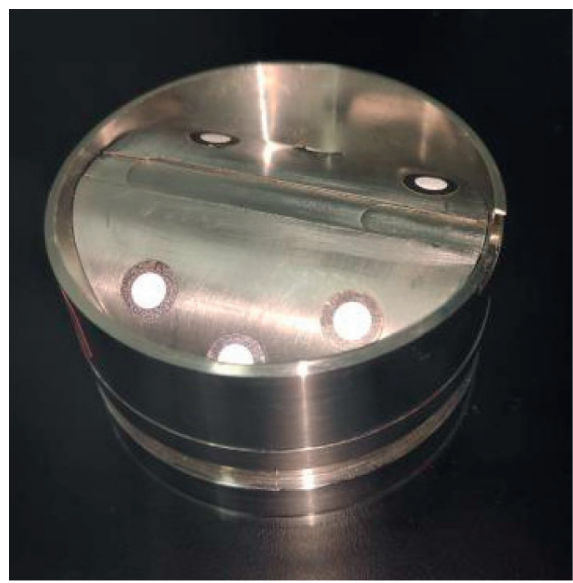

(b)

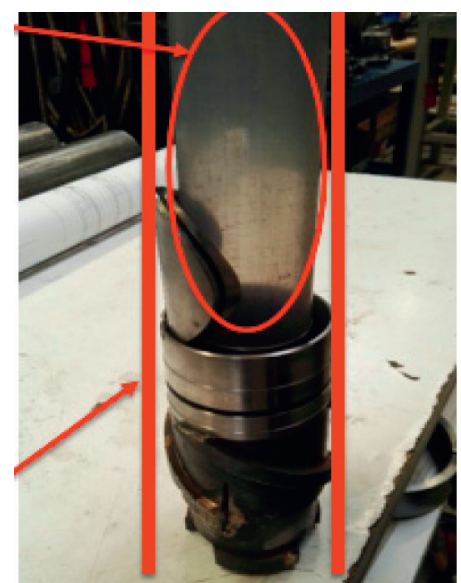

(c)

Figure 1: Square cover solid drawing.

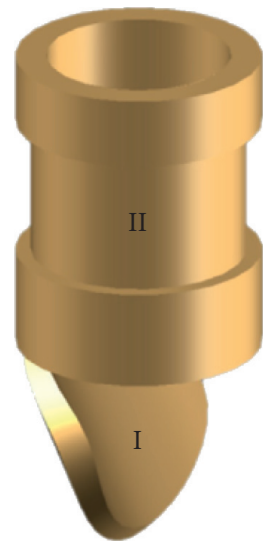

(a)

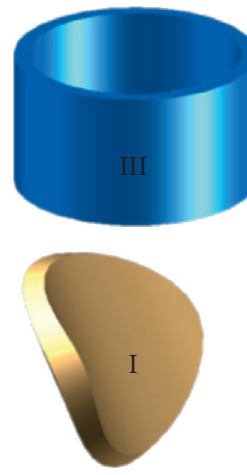

(b)

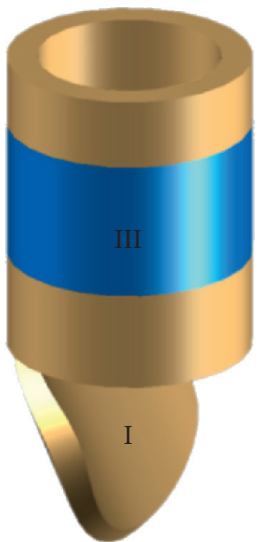

(c)

Figure 2: Permanent magnet valve seat design diagram. I, the valve cover. II, the valve seat. III, permanent magnet.

magnetic base makes the valve cover flip and close. The force diagram at a certain moment in the process is shown in Figure 3. After the valve cover is closed, the magnetic force causes the valve cover to close tightly against the valve seat to form a static magnetic seal.

\subsection{Simplification of the Mechanical Model Based on Magnetic} Field Control. The dominant factors of the magnetic force are determined by the coercivity, the size of the permanent magnet, and the distance between the permanent magnet and the desired point. The coercivity is determined by the permanent magnet material. The size of the permanent magnet is determined within a limited range. The magnetic force at a certain position during the rotation of the valve cover varies according to the distance between the valve cover and the permanent magnet. Therefore, when simplifying the mechanical model, the main research point is the change in the magnetic force caused by the change in the distance. The valve cover is simplified as a thick round plate, and the valve seat is

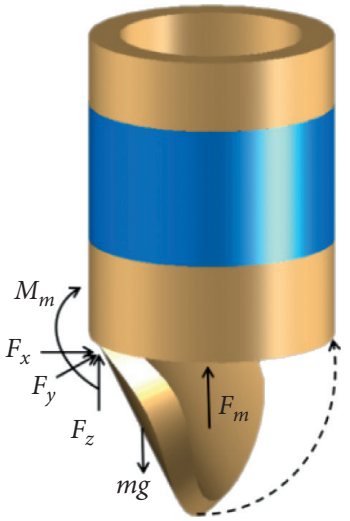

Figure 3: Schematic diagram of the force applied at a certain moment during the valve cover closure.

simplified as a permanent magnet cylinder. The valve cover is subject to only two forces in the magnetic field, namely, gravity and the magnetic force generated by the valve seat. If the magnetic force is greater than gravity, 
then the valve cover will overcome gravity under the magnetic force to render a variable acceleration linear motion. And the valve seat will finally close. The force exerted on the valve cover under the valve seat is shown in Figure 4. The magnetic force of the valve cover attenuates with the increase in the distance between the valve cover and the valve seat [45]. How to weaken the relationship between the magnetic force and the distance is the main goal of model establishment and optimization. Therefore, it is important to explore different magnetic circuit design schemes and seek magnetic optimization schemes for long-distance traction.

\section{Exploration of the Magnetic Field Spatial Distribution}

3.1. Magnetic Circuit Design. In magnetic mechanical design, an optimized magnetic element usually has multiple magnetizing directions [46]. Based on the Hibachi array principle [46, 47], divide the permanent magnet valve seat into two identical shape tile magnets, four identical shape tile magnets, and eight identical shape tile magnets along the axis, as shown in Figure 5. The spatial distribution of the magnetic field of the valve seat will be optimized through the comprehensive comparison and analysis of the magnetic flux density norm and magnetic force.

Two kinds of magnetizing methods, namely, axial and annular, are selected, as shown in Figure 6.

When the valve seat consists of two identical shape tile magnets, three magnetic field combinations are offered. When the valve seat consists of four identical shape tile magnets, six magnetic field combinations are offered. When the valve seat consists of eight identical shape tile magnets, six magnetic field combinations are offered. A total of fifteen magnetic field combinations are designed. The magnetic circuit design schemes are shown in Figures 7-9.

3.2. Basic Parameter Setting. According to the actual size of the coring device, the inner diameter of the simplified valve seat is $60 \mathrm{~mm}$, the outer diameter is $80 \mathrm{~mm}$, and the height is $45 \mathrm{~mm}$. The simplified seat has a diameter of $80 \mathrm{~mm}$ and a height of $5 \mathrm{~mm}$. The maximum distance between the center point of the inner surface of the valve cover and the center point of the sealing surface of the valve seat is $34 \mathrm{~mm}$. Therefore, 8 monitoring positions are set between the seat and the valve cover; that is, the distances between the seat and the valve cover are $1 \mathrm{~mm}$, $5 \mathrm{~mm}, 10 \mathrm{~mm}, 15 \mathrm{~mm}, 20 \mathrm{~mm}, 25 \mathrm{~mm}, 30 \mathrm{~mm}$, and $35 \mathrm{~mm}$. In this paper, COMSOL Multiphysics is adopted for numerical simulation analysis. The air region is established outside the coring device. The valve cover is made of silicon steel. The seat material is N52 NFeB. The outer edge of the air region is set as a zero magnetic scalar potential, and the steady-state model is used for calculation according to Figures 2 and 7-9. The average meshing quality interval is $0.758-0.786$.

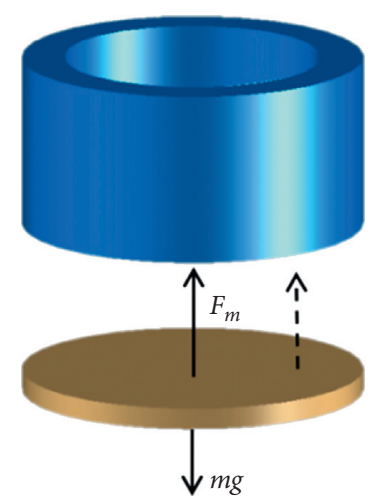

Figure 4: A simplified mechanical model of the valve cover at a certain position.

\subsection{Analysis of the Calculation Results When the Valve Seat Consists of Two Identical Shape Tile Magnets}

3.3.1. Magnetic Flux Density Norm Analysis. The magnetic flux density norm reflects a stress relationship between the valve seat and the valve cover. When the valve cover is in the magnetic field generated by the valve seat, the greater the magnetic flux density norm of the valve cover is and the tighter the stress relationship between the valve cover and the valve seat is [45]. According to Figure 7, a magnetic field simulation is carried out to generate three completely different magnetic field distributions. The magnetic flux density norm nephogram of the valve cover is shown in Figure 10. According to the figure, the magnetic flux density norm of the valve cover decreases with increasing distance between the valve cover and the valve seat in each scheme. In Scheme 1, the maximum value of the cover flux density norm is in the outermost region of the valve cover. When the valve cover is more than $15 \mathrm{~mm}$ from the valve seat, the maximum value is four disconnected point areas. In Scheme 2, when the valve cover is close to the valve seat, the maximum value of the valve cover flux density norm occurs at two symmetric areas on the outermost side. When the cover is more than $15 \mathrm{~mm}$ from the seat, the maximum value is a concentrated in an oval area. In Scheme 3, when the valve cover is close to the valve seat, the maximum value of the valve cover flux density norm occurs at two symmetric areas on the outermost side. When the cover is more than $15 \mathrm{~mm}$ from the seat, the maximum value is a concentrated line area. Among the three schemes, the flux density norm of the valve cover of Scheme 2 is the optimal value at the same position from the valve seat, followed by Scheme 3 and Scheme 1. In summary, from the perspective of the magnetic flux density norm, the advantages of the three schemes suggest the following ranking: Scheme 2, Scheme 3, and Scheme 1.

3.3.2. Magnetic Force Analysis. The relationship between the distance and maximum magnetic force is fitted according to Table 1, and the fitting curve is shown in Figure 11.

All three schemes can be described by a logistic fitting function, and the fitting degrees exceed 0.9. The three fitting 


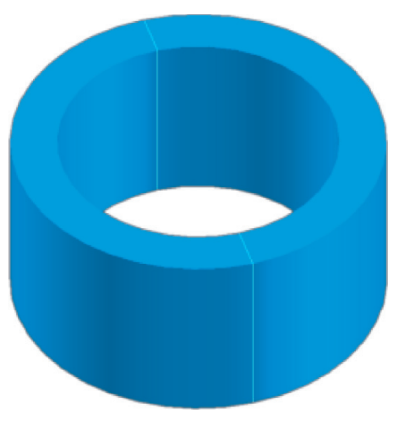

(a)

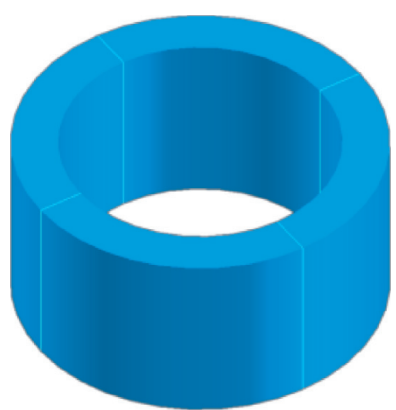

(b)

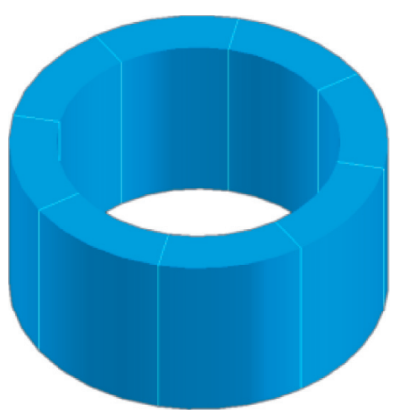

(c)

Figure 5: The valve seat is divided into identical shape tiles. (a) Two identical shape tile magnets. (b) Four identical shape tile magnets. (c) Eight identical shape tile magnets.

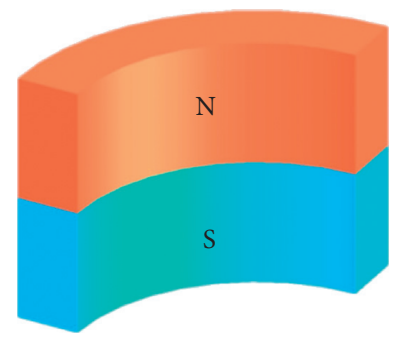

(a)

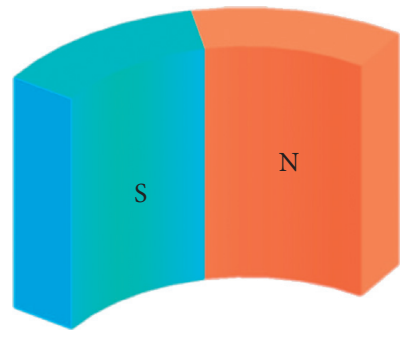

(b)

FIgURE 6: Magnetizing mode of the tile magnet. (a) Axial magnetization. (b) Circular magnetization.

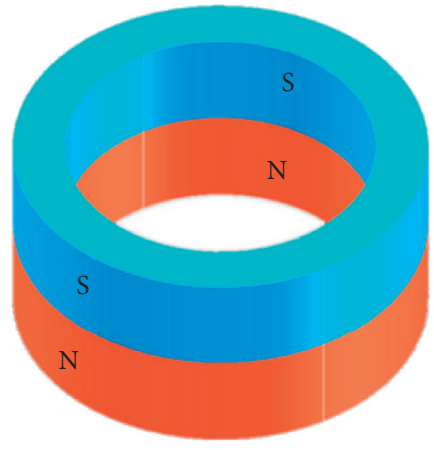

(a)

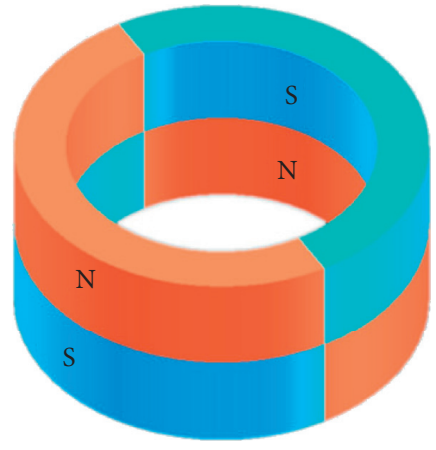

(b)

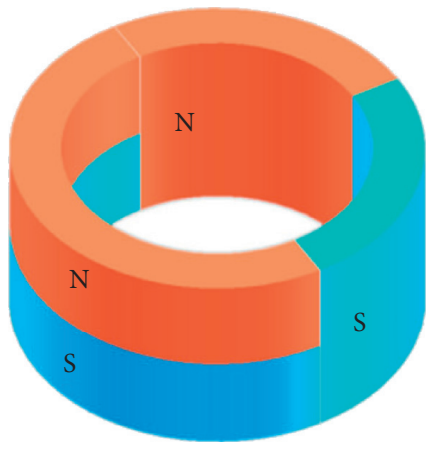

(c)

Figure 7: Magnetic circuit design scheme when the valve seat consists of two identical shape tile magnets. (a) Scheme 1. (b) Scheme 2. (c) Scheme 3 .

curves show the same trend, and the fitting function is as follows:

$$
F=\frac{\left(A_{1}-A_{2}\right)}{\left(1+\left(x / A_{3}\right)^{p}\right)+A_{2}},
$$

where $F$ represents the maximum magnetic force exerted on the valve cover, $A_{1}, A_{2}, A_{3}$, and $P$ are constant coefficients, and $x$ is the distance between the valve cover and the valve seat. Formula (1) shows that there is a close relationship between the maximum magnetic force and distance, showing a nonlinear negative correlation. In the fitting formula, $P$ is the negative correlation coefficient, and the $P$ values are 2.138, 1.712, and 1.808 for Schemes 1-3, respectively. Thus, the negative correlation between the magnetic force and distance is the smallest in Scheme 2. According to Figure 11, the curve of Scheme 2 plots above the other two curves, indicating that the maximum magnetic force of the valve cover of Scheme 2 is the optimal value at the same position from the valve seat. In summary, from the perspective of magnetic force, the advantages of the three schemes results in the following ranking: Scheme 2, Scheme 1, and Scheme 3.

In summary, when the valve seat consists of two identical shape tile magnets, Scheme 2 is the optimal scheme. 


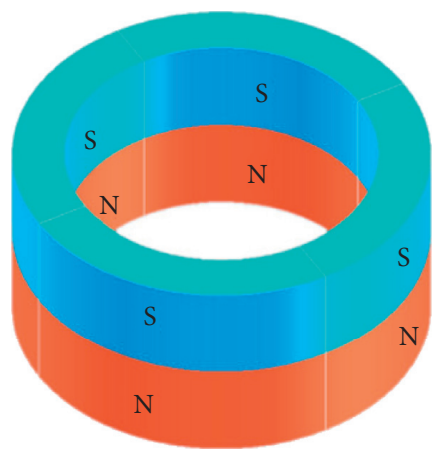

(a)

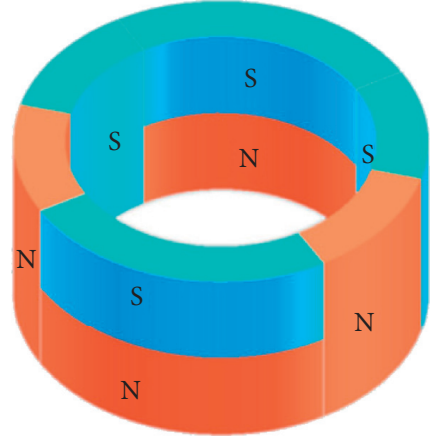

(d)

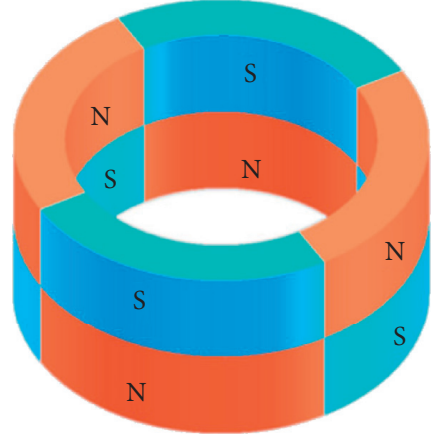

(b)

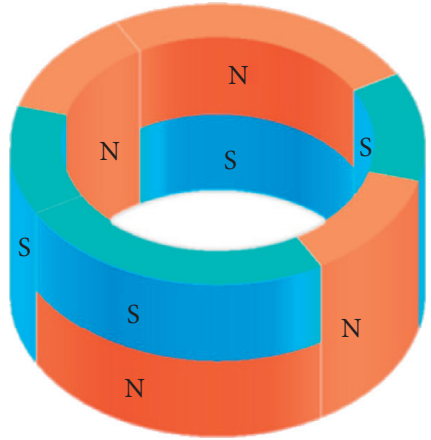

(e)

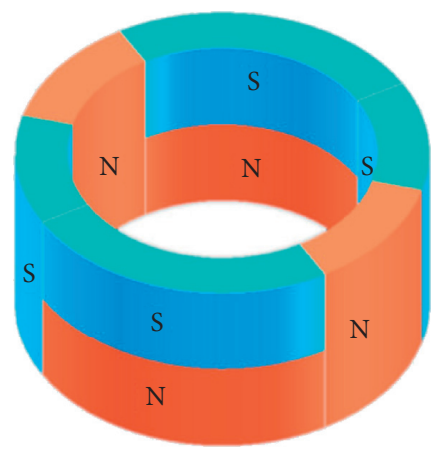

(c)

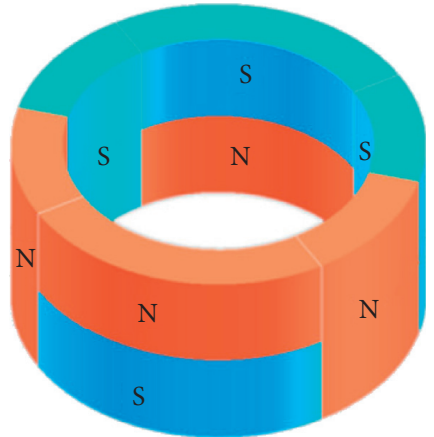

(f)

FigURE 8: Magnetic circuit design scheme when the valve seat consists of four identical shape tile magnets. (a) Scheme 4 . (b) Scheme 5. (c) Scheme 6. (d) Scheme 7. (e) Scheme 8. (f) Scheme 9.

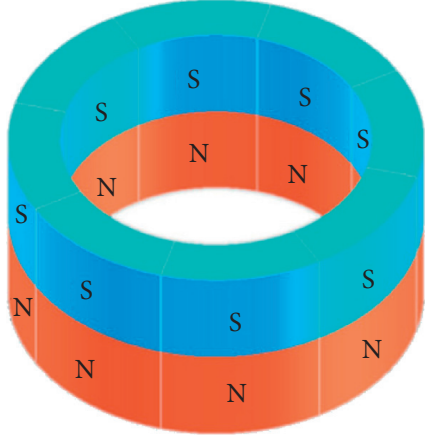

(a)

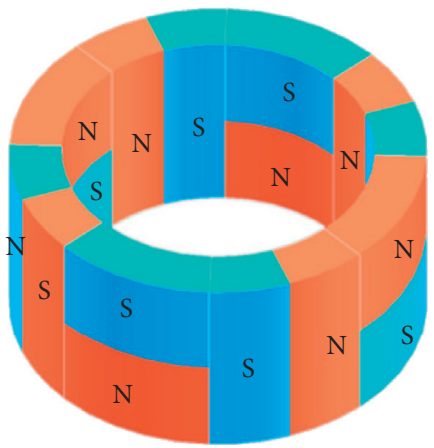

(d)

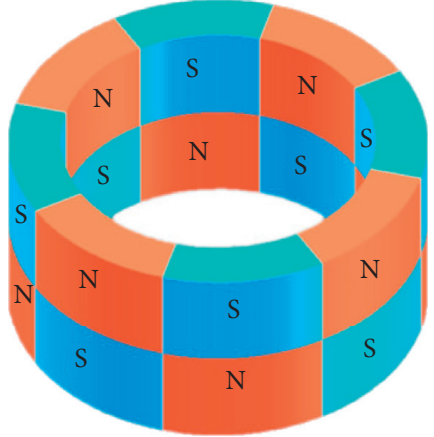

(b)

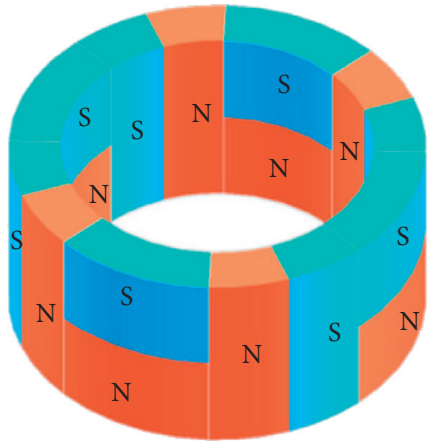

(e)

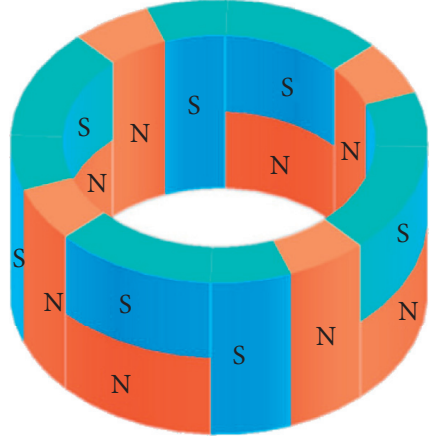

(c)

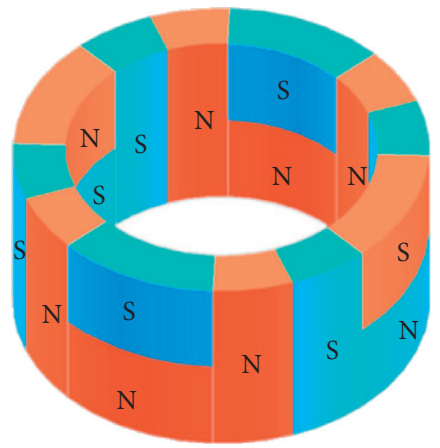

(f)

Figure 9: Magnetic circuit design scheme when the valve seat consists of eight identical shape tile magnets. (a) Scheme 10. (b) Scheme 11. (c) Scheme 12. (d) Scheme 13. (e) Scheme 14. (f) Scheme 15. 


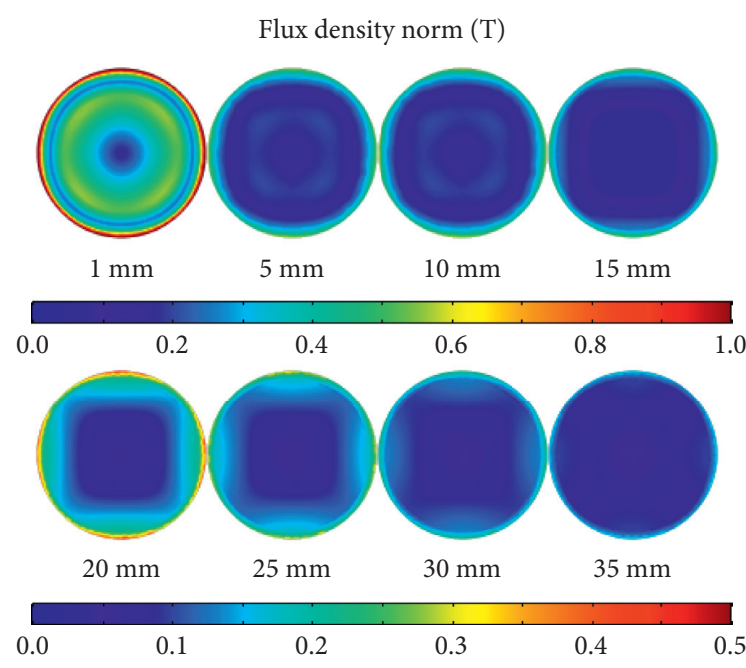

(a)

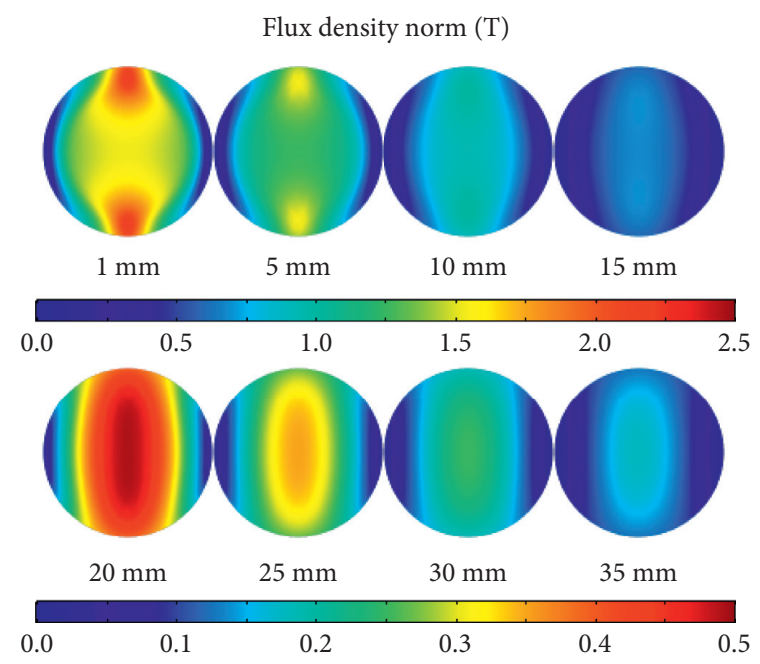

(b)

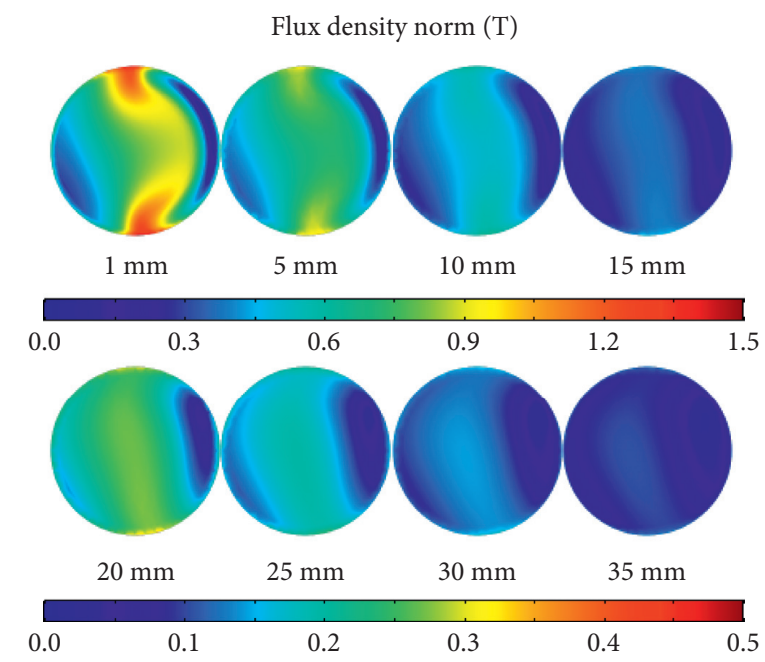

(c)

Figure 10: Magnetic flux density norm nephogram of the valve cover when the valve seat consists of two identical shape tile magnets. (a) Scheme 1. (b) Scheme 2. (c) Scheme 3.

TABle 1: Maximum magnetic force of the valve cover when the valve seat consists of two identical shape tile magnets in three schemes.

\begin{tabular}{lccc}
\hline \multirow{2}{*}{ Distance $(\mathrm{mm})$} & \multicolumn{3}{c}{ Maximum magnetic force $(\mathrm{N})$} \\
& Scheme 1 & Scheme 2 & Scheme 3 \\
\hline 1 & 259.329 & 354.435 & 161.725 \\
5 & 68.370 & 131.817 & 53.001 \\
10 & 19.124 & 49.643 & 18.332 \\
15 & 7.851 & 22.130 & 7.991 \\
20 & 4.380 & 10.368 & 3.926 \\
25 & 2.817 & 5.049 & 2.077 \\
30 & 1.859 & 2.486 & 1.158 \\
35 & 1.179 & 1.229 & 0.661 \\
\hline
\end{tabular}

\subsection{Analysis of the Calculation Results When the Valve Seat Consists of Four Identical Shape Tile Magnets}

3.4.1. Magnetic Flux Density Norm Analysis. According to Figure 8 , magnetic field simulation is carried out to generate six completely different magnetic field distributions. The magnetic flux density norm nephogram of the valve cover is shown in Figure 12. According to the figure, the magnetic flux density norm of the valve cover decreases with increasing the distance between the valve cover and the valve seat in each scheme. The analysis method is the same as that used in Section 3.3. In Scheme 9, at the same distance from the valve seat, the valve cover flux density norm distribution is radial, with the maximum value at the center of the valve cover. In addition, the maximum value is distributed across a wide area, forming a square at close distance and an oval at long distance. The valve cover flux density norm of Scheme 9 tends to decrease when the distance between the valve cover and the valve seat is large, but in this case, the valve cover flux density norm is larger and more concentrated than in other schemes. Among the six schemes, the flux density norm of the valve cover of Scheme 9 is the optimal value at the same position from the valve seat. In summary, from the perspective of the magnetic flux density norm, the advantages of the schemes result in the following 


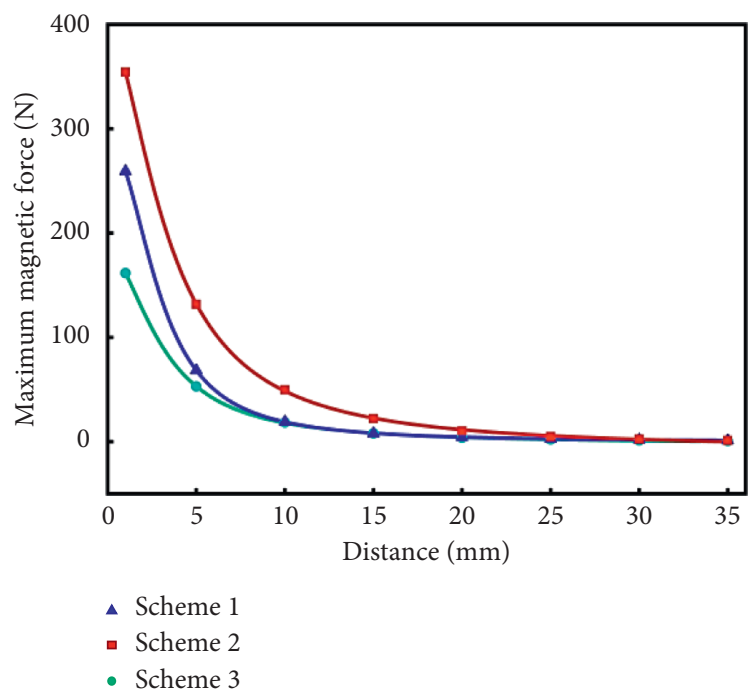

FIgURE 11: The curve of the relationship between the maximum magnetic force and distance when the valve seat consists of two identical shape tile magnets.

ranking: Scheme 9, Scheme 8, Scheme 7, Scheme 5, Scheme 6, and Scheme 4.

3.4.2. Magnetic Force Analysis. The relationship between the distance and maximum magnetic force is fitted according to Table 2, and the fitting curve is shown in Figure 13.

All 6 schemes can be described by fitting formula (1), and the fitting degrees exceed 0.9 . The $P$ values are $2.265,1.855$, $1.958,1.844,1.486$, and 1.311 for Schemes $4-9$, respectively. Thus, the negative correlation between the magnetic force and distance is the smallest in Scheme 9. According to Figure 13, the curve of Scheme 9 is above the other five curves when the distance between the valve cover and the valve seat exceeds $10 \mathrm{~mm}$. This indicates that when the cover is far from the seat, the maximum magnetic force of the valve cover of Scheme 9 is the optimal value at the same position. In summary, from the perspective of magnetic force, the advantages of the schemes result in the following ranking: Scheme 9, Scheme 8, Scheme 4, Scheme 7, Scheme 5, and Scheme 6.

In summary, when the valve seat consists of four identical shape tile magnets, Scheme 9 is the optimal scheme.

\subsection{Analysis of the Calculation Results When the Valve Seat Consists of Eight Identical Shape Tile Magnets}

3.5.1. Magnetic Flux Density Norm Analysis. According to Figure 9, magnetic field simulation is carried out to generate six completely different magnetic field distributions. The magnetic flux density norm nephogram of the valve cover is shown in Figure 14. According to the figure, the magnetic flux density norm of the valve cover decreases with increasing the distance between the valve cover and the valve seat in each scheme. The analysis method is the same as that in Section 3.3. In Scheme 15, the magnetic flux density mode is generally low in the center and high at the peripheries in a symmetric distribution. The outer ring of the valve seat has four large areas in which the magnetic flux density mode is more uniform and is generally higher than it is in other schemes. Among the six schemes, the flux density norm of the valve cover of Scheme 15 is the optimal value at the same position from the valve seat. In summary, from the perspective of the magnetic flux density norm, the advantages of the schemes result in the following ranking: Scheme 15, Scheme 14, Scheme 13, Scheme 11, Scheme 12, and Scheme 10.

3.5.2. Magnetic Force Analysis. The relationship between the distance and maximum magnetic force is fitted according to Table 3, and the fitting curve is shown in Figure 15.

All 6 schemes can be described by fitting formula (1), and the fitting degrees exceed 0.9 . The $P$ values are $2.220,2.484$, $2.332,2.042,1.894$, and 1.706 for Schemes 10-15, respectively. Thus, the negative correlation between the magnetic force and distance is the smallest in Scheme 15. According to Figure 15, the curve of Scheme 15 plots above the other five curves when the distance between the valve cover and the valve seat exceeds $5 \mathrm{~mm}$. This indicates that when the cover is far from the seat, the maximum magnetic force of the valve cover of Scheme 15 is the optimal value at the same position. Although the curve fluctuates at $35 \mathrm{~mm}$, the overall trend is clear. In summary, from the perspective of magnetic force, the advantages of the schemes result in the following ranking: Scheme 15, Scheme 10, Scheme 13, Scheme 12, Scheme 14, and Scheme 11.

In summary, when the valve seat consists of eight identical shape tile magnets, Scheme 15 is the optimal scheme.

3.6. Comparative Analysis of the Magnetic Field Optimization. According to the above sections, three comparison schemes are selected: Scheme 2, when the valve seat consists of two identical shape tile magnets; Scheme 9, when the valve seat 


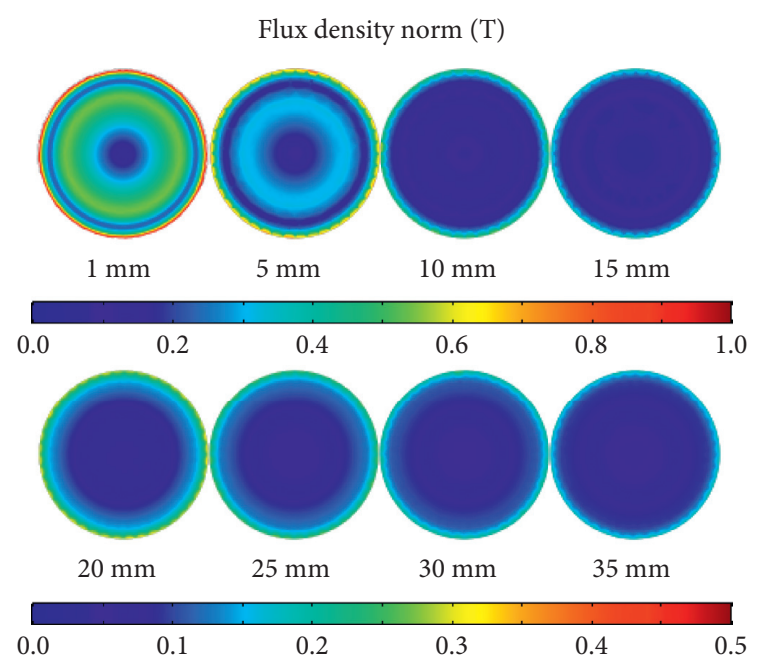

(a)

Flux density norm $(\mathrm{T})$

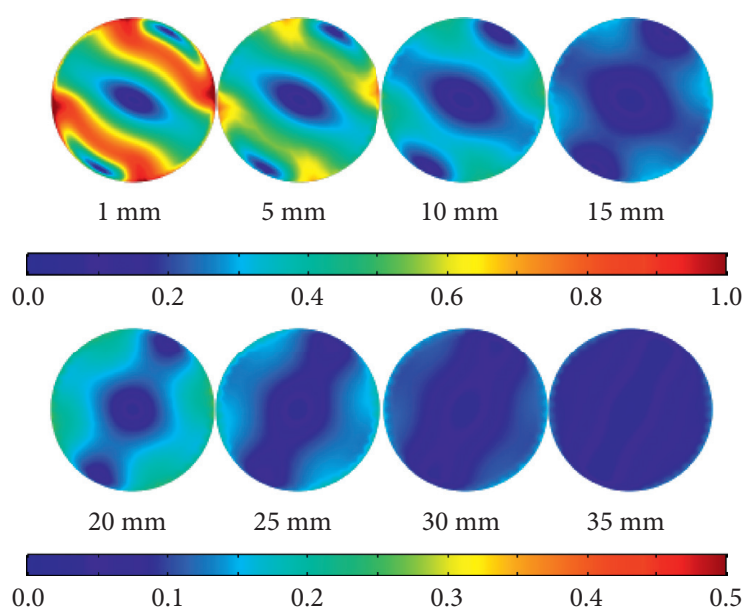

(c)

Flux density norm (T)
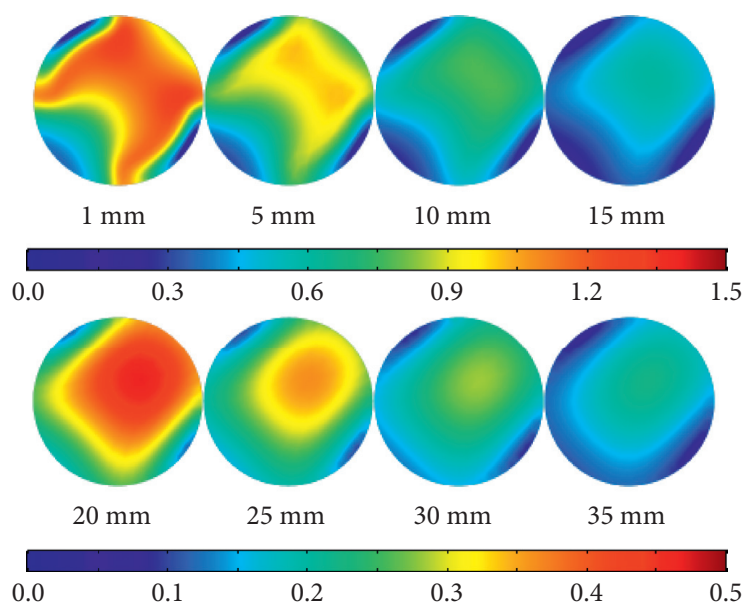

(e)

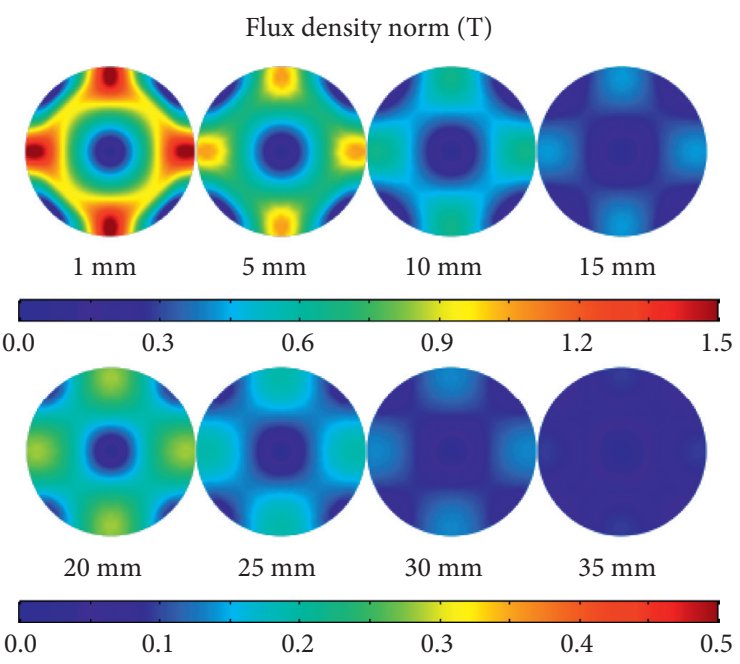

(b)

Flux density norm $(\mathrm{T})$
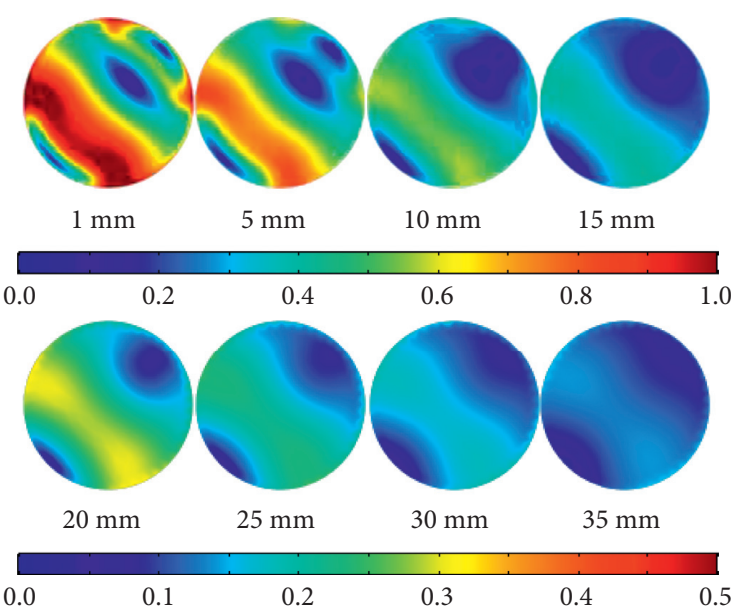

(d)

Flux density norm $(\mathrm{T})$
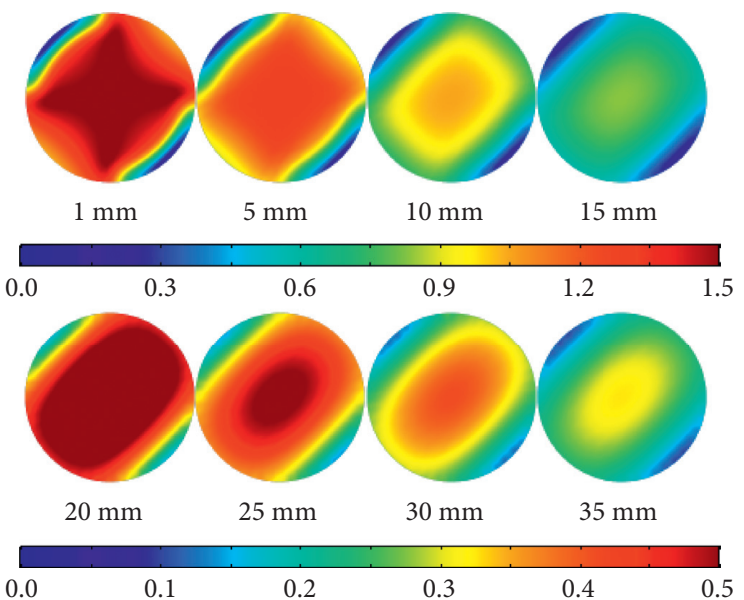

(f)

FIGURE 12: Magnetic flux density norm nephogram of the valve cover when the valve seat consists of four identical shape tile magnets. (a) Scheme 4. (b) Scheme 5. (c) Scheme 6. (d) Scheme 7. (e) Scheme 8. (f) Scheme 9. 
TABLE 2: Maximum magnetic force of the valve cover when the valve seat consists of four identical shape tile magnets in six schemes.

\begin{tabular}{|c|c|c|c|c|c|c|}
\hline \multirow{2}{*}{ Distance $(\mathrm{mm})$} & \multicolumn{6}{|c|}{ Maximum magnetic force $(\mathrm{N})$} \\
\hline & Scheme 4 & Scheme 5 & Scheme 6 & Scheme 7 & Scheme 8 & Scheme 9 \\
\hline 1 & 265.098 & 344.533 & 169.530 & 171.384 & 190.576 & 236.777 \\
\hline 5 & 64.168 & 111.624 & 52.093 & 53.455 & 67.263 & 97.531 \\
\hline 10 & 16.374 & 37.288 & 16.272 & 17.915 & 27.857 & 46.035 \\
\hline 15 & 6.575 & 14.886 & 6.697 & 7.862 & 13.646 & 24.548 \\
\hline 20 & 3.369 & 6.221 & 3.027 & 3.873 & 7.242 & 13.931 \\
\hline 25 & 2.174 & 2.749 & 1.534 & 2.120 & 4.042 & 8.028 \\
\hline 30 & 1.552 & 1.247 & 0.843 & 1.238 & 2.287 & 4.806 \\
\hline 35 & 1.151 & 0.586 & 0.512 & 0.771 & 1.350 & 2.915 \\
\hline
\end{tabular}

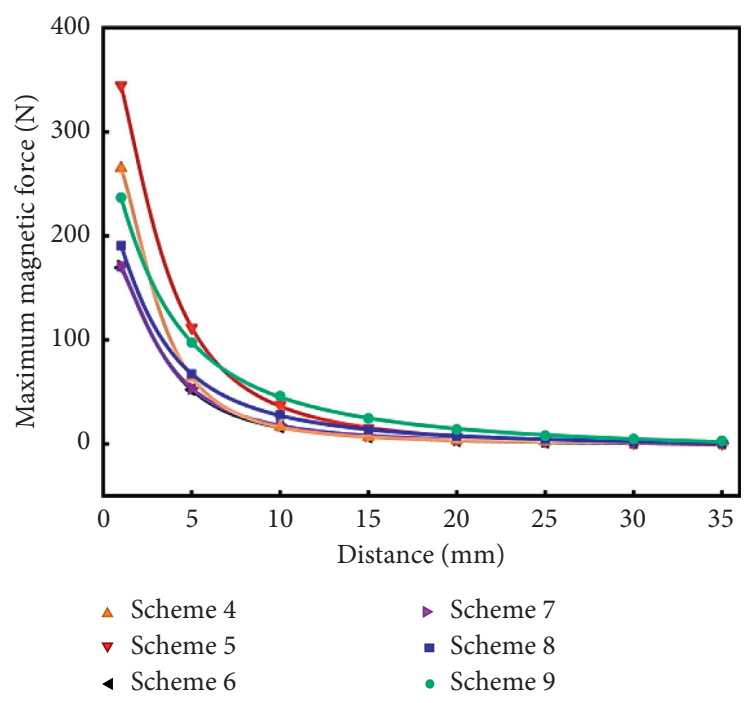

FIGURE 13: The curve of the relationship between the maximum magnetic force and distance when the valve seat consists of four identical shape tile magnets.

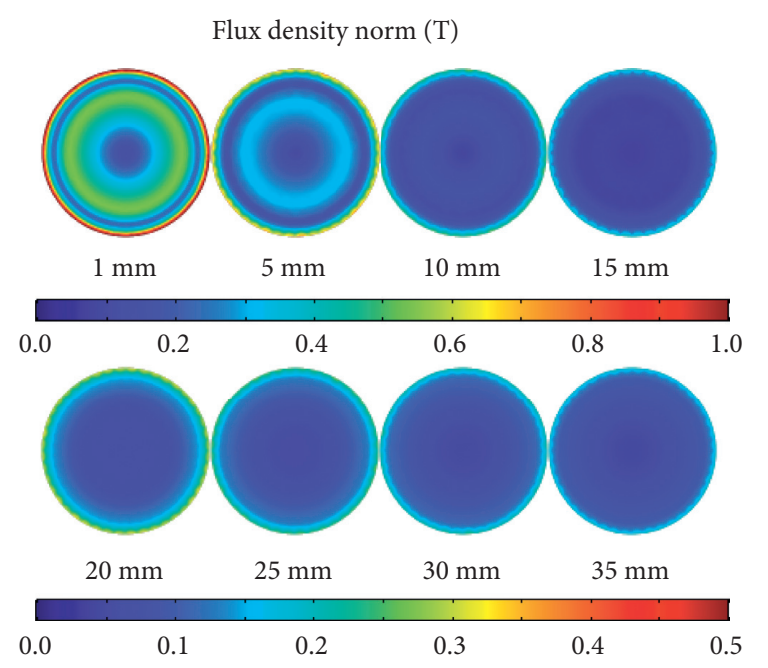

(a)

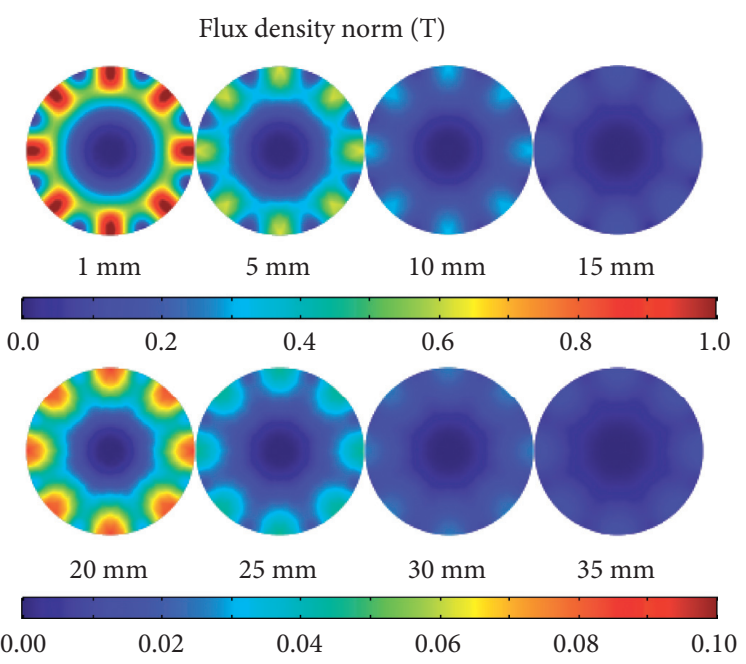

(b)

Figure 14: Continued. 


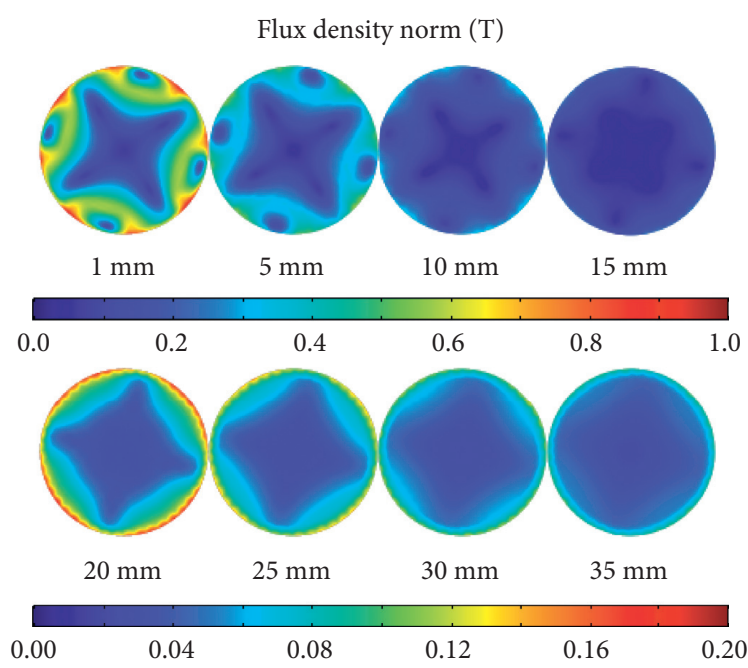

(c)

Flux density norm (T)
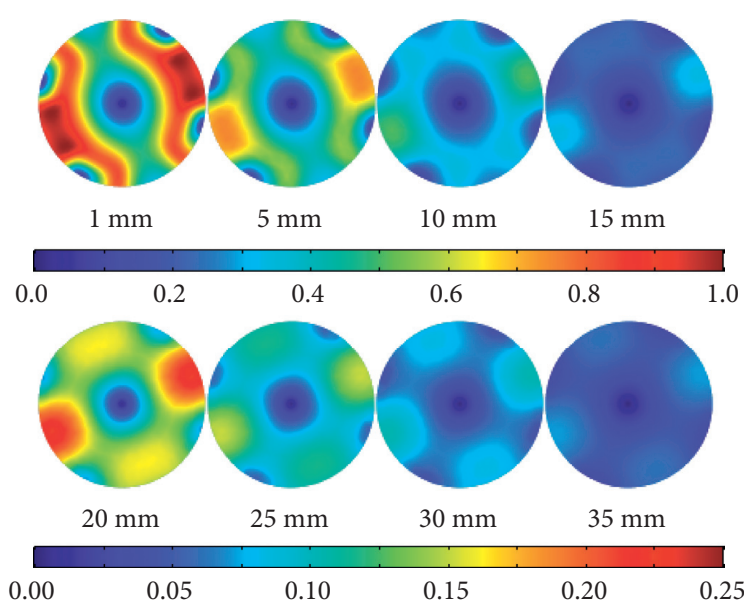

(e)

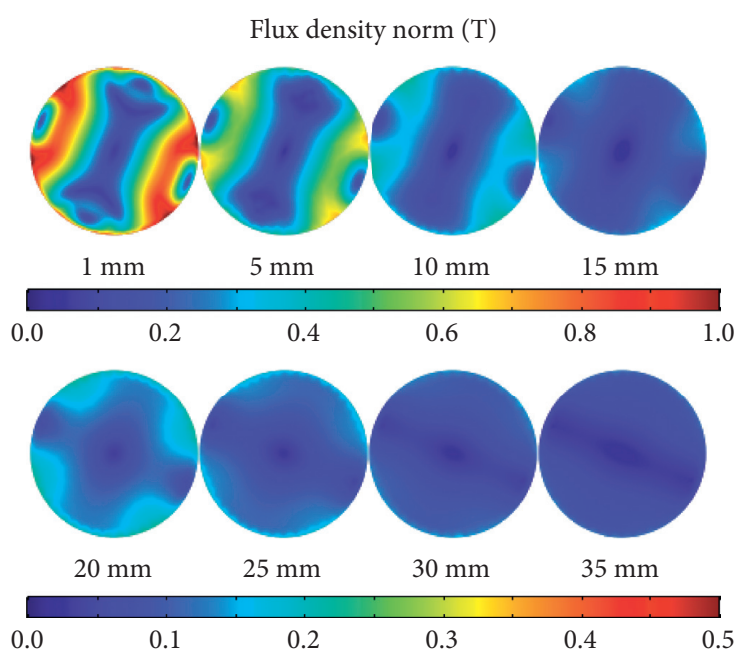

(d)

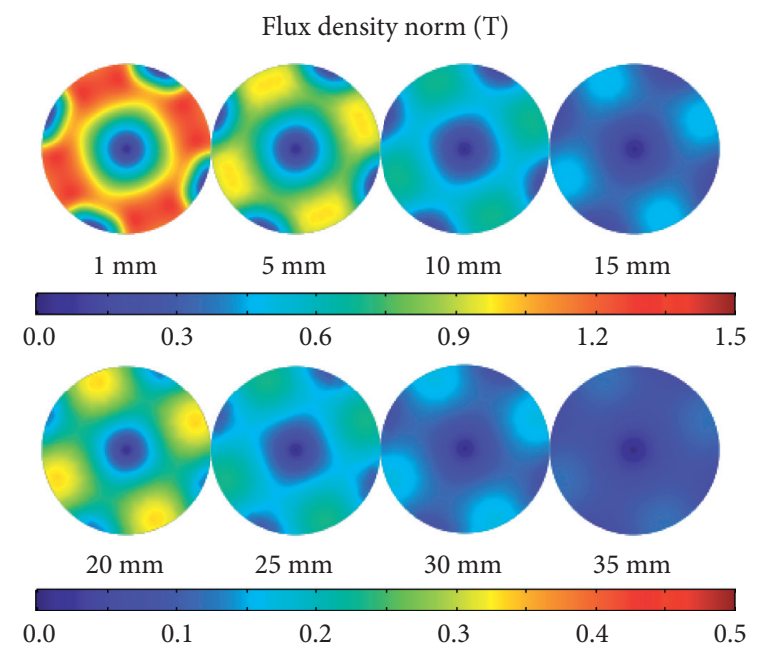

(f)

Figure 14: Magnetic flux density norm nephogram of the valve cover when the valve seat consists of eight identical shape tile magnets. (a) Scheme 10. (b) Scheme 11. (c) Scheme 12. (d) Scheme 13. (e) Scheme 14. (f) Scheme 15.

TABLE 3: Maximum magnetic force of the valve cover when the valve seat consists of eight identical shape tile magnets in six schemes.

\begin{tabular}{|c|c|c|c|c|c|c|}
\hline \multirow{2}{*}{ Distance $(\mathrm{mm})$} & \multicolumn{6}{|c|}{ Maximum magnetic force $(\mathrm{N})$} \\
\hline & Scheme 10 & Scheme 11 & Scheme 12 & Scheme 13 & Scheme 14 & Scheme 15 \\
\hline 1 & 264.869 & 328.353 & 175.293 & 182.453 & 199.339 & 286.889 \\
\hline 5 & 62.423 & 75.978 & 41.999 & 48.249 & 62.507 & 112.262 \\
\hline 10 & 16.285 & 16.184 & 10.078 & 13.940 & 20.242 & 43.513 \\
\hline 15 & 6.516 & 3.910 & 3.130 & 5.233 & 7.948 & 18.762 \\
\hline 20 & 3.384 & 0.957 & 1.228 & 2.339 & 3.278 & 8.315 \\
\hline 25 & 2.189 & 0.256 & 0.652 & 1.228 & 1.434 & 3.850 \\
\hline 30 & 1.561 & 0.071 & 0.421 & 0.711 & 0.651 & 1.834 \\
\hline 35 & 1.168 & 0.020 & 0.301 & 0.447 & 0.300 & 0.867 \\
\hline
\end{tabular}




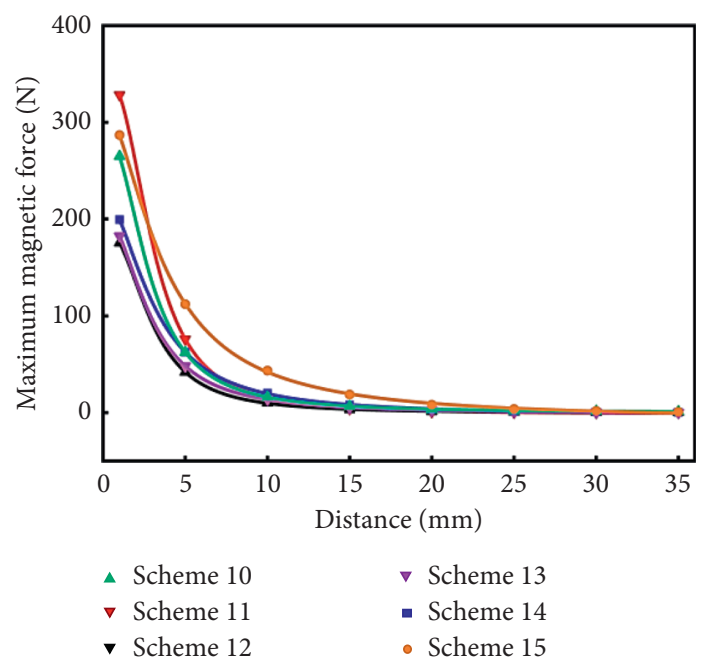

FIGURE 15: The curve of the relationship between the maximum magnetic force and distance when the valve seat consists of eight identical shape tile magnets.

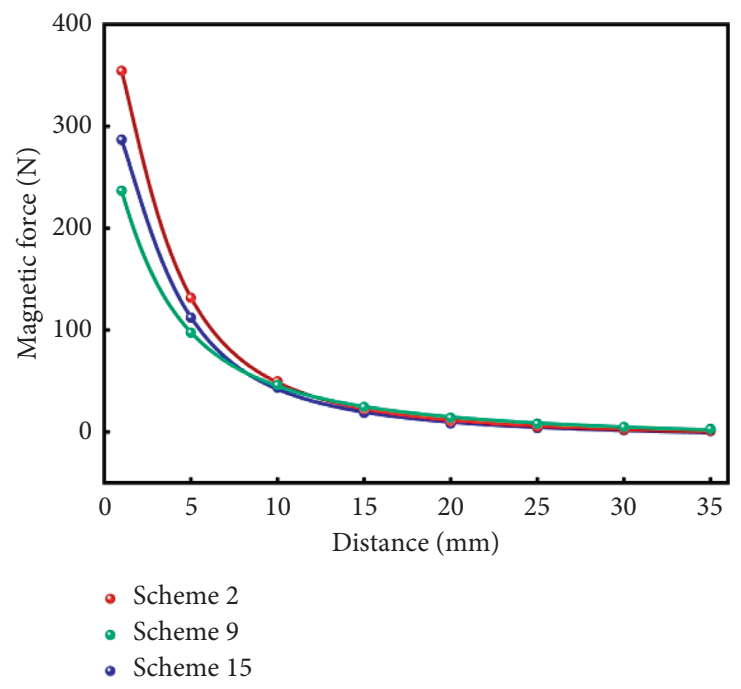

FIGURE 16: Relationships of the maximum magnetic force and distance of the monitoring point with fitting curves for three schemes.

consists of four identical shape tile magnets; and Scheme 15, when the valve seat consists of eight identical shape tile magnets. By comparing Figures 10, 12, and 14, it is found that the magnetic flux density norm of the three schemes is relatively concentrated. However, from the observation of the whole trend, Scheme 9 of the magnetic flux density norm is more concentrated, and it is superior to other schemes at monitoring points farther than $10 \mathrm{~mm}$. Figure 16 shows the fitting curve of the magnetic force exerted on the valve cover and the distance between the valve cover and the valve seat in the three schemes. According to the information of the figure, at close range, the magnetic force generated by Scheme 2 is relatively large, and it is conducive to magnetic sealing; the magnetic force of the three schemes is much greater than the gravity of the valve cover, so there is no need to consider the traction problem at close range. When the distance is greater than $10 \mathrm{~mm}$, the magnetic force generated by Scheme 9 gradually surpasses the other two schemes and becomes the optimal scheme. By comparing the negative correlation parameter $P$ of the three schemes, it can be seen that the $P$ value of Scheme 9 is the smallest at 1.311. This means that the magnetic force of Scheme 9 decays more slowly with distance than those of the other schemes. Therefore, the optimal scheme is Scheme 9. The scheme generates $2.915 \mathrm{~N}$ magnetic force when the valve cover is $35 \mathrm{~mm}$ from the seat, which is greater than the $2.25 \mathrm{~N}$ gravity 
of the valve cover itself. Therefore, the feasibility of a magnetic trigger can be verified under the magnetic circuit design of this scheme.

\section{Conclusions}

In this paper, based on the past development of pressureretaining controllers, an innovative design for a pressureretaining controller triggered by a magnetic force is presented. Based on the Hibachi array principle, fifteen varieties of magnetic circuit design schemes are proposed. The magnetic field is analyzed through numerical simulation, which avoids the problems that the magnetic field is difficult to solve analytically and that the accuracy of an empirical formula is low. Through this exploratory study, the mechanical feasibility of a magnetic trigger is clarified, and a feasibility analysis is provided for this magnetic trigger. This work provides new opportunities for in situ pressure-retaining coring of deep rock masses. The specific conclusions are as follows:

(1) An innovative design for a pressure-retaining controller based on a magnetic trigger is proposed to realize flip closure under any circumstances and magnetic sealing effects. The technique can be applied to coring a target formation in any direction in areas such as a coal mine or shale gas field.

(2) Considering all the results, the magnetic flux density norm is more concentrated when the valve seat consists of four identical shape tile magnets (Scheme 9), and this scheme is superior to other schemes when the monitoring point distance is greater than $10 \mathrm{~mm}$.

(3) The optimal scheme under the long-distance traction condition is Scheme 9. The magnetic force of this scheme decays more slowly with distance than those of the other schemes. The valve cover's magnetic force $35 \mathrm{~mm}$ from the valve seat is $2.915 \mathrm{~N}$, which is greater than the gravity of the valve cover of $2.25 \mathrm{~N}$. The valve cover can close against gravity, which verifies the feasibility of a magnetic field-triggered pressure-retaining controller.

(4) The composite of multipole magnetization helps to weaken the nonlinear negative correlation between the magnetic force and distance. The composite magnetization combination of the same monitoring point has a greater magnetic flux density norm and magnetic force. For this valve seat, the number of magnetic poles is four.

\section{Data Availability}

The raw/processed data required to reproduce these findings cannot be shared at this time as the data also form part of an ongoing study.

\section{Conflicts of Interest}

The authors declare that they have no conflicts of interest regarding the publication of this paper.

\section{Acknowledgments}

This study was funded by the National Natural Science Foundation of China (Grant nos. 51822403 and 51827901) and the Sichuan International Technological Innovation Cooperation Project (Grant no. 2018HH0159).

\section{References}

[1] H. Xie, F. Gao, J. U. Yang et al., "Novel idea and disruptive technologies for the exploration and research of deep earth," Advanced Engineering Sciences, vol. 1, no. 49, pp. 1-8, 2017.

[2] F. Gong, W. Wuxing Wu, T. Tianbin Li, and X. Xuefeng Si, "Experimental simulation and investigation of spalling failure of rectangular tunnel under different three-dimensional stress states," International Journal of Rock Mechanics and Mining Sciences, vol. 122, Article ID 104081, 2019.

[3] M. Gao, S. Zhang, J. Li et al., "The dynamic failure mechanism of coal and gas outbursts and response mechanism of support structure," Thermal Science, vol. 23, p. 122, 2019.

[4] F.-Q. Gong, X.-F. Si, X.-B. Li, and S.-Y. Wang, "Experimental investigation of strain rockburst in circular caverns under deep three-dimensional high-stress conditions," Rock Mechanics and Rock Engineering, vol. 52, no. 5, pp. 1459-1474, 2019.

[5] H. Xie, "Research framework and anticipated results of deep rock mechanics and mining theory," Advanced Engineering Science, vol. 2, no. 49, pp. 1-16, 2017.

[6] H. Xie, M. Gao, R. Hang et al., "Study on concept and progress of in situ fidelity coring of deep rocks," Chinese Journal of Rock Mechanics and Engineering, vol. 39, no. 5, pp. 865-876, 2020.

[7] J. Xi, X. Wang, Y. Yang et al., "Application of coring technology with keeping pressure in Lingjian 14-241 well in tuha oilfield," Petroleum Drilling Techniques, vol. 31, no. 3, pp. 19-21, 2003.

[8] L. Ma, J. Li, R. Hua et al., "An analysis method for reservoir fluid saturation by pressure coring: a case study from Quaternary biogenetic gas reservoirs in the Tainan Gas Field, Qaidam Basin,” Natural Gas Industry, vol. 36, no. 1, pp. 76-80, 2016.

[9] R. Wang, L. Zhang, H. Sun et al., "Progress in key technologies for handling natural gas hydrate cores from ocean sediments," Geological Science and Technology Information, vol. 36, no. 2, pp. 249-257, 2017.

[10] Y. Bai and Q. Li, "Progress on natural gas hydrate sampling techniques and tools," Petroleum Drilling Techniques, vol. 38, no. 6, pp. 116-123, 2010.

[11] H. L. Hu, H. X. Tang, J. F. Luo et al., "Deepwater gas hydrates drilling and coring techniques," Oil Drilling and Production Technology, vol. 31, no. 1, pp. 27-29, 2009.

[12] Y. S. Wang, Y. Q. Wang, L. X. Kuang et al., "Study and application of $152.4 \mathrm{~mm}$ coalbed methane coring tool by rope," China Petroleum Machinery, vol. 39, no. 1, pp. 31-33, 2011.

[13] X. Wang, D. Zou, L. Yang et al., "Design of a pressurepreservation coring tool for deep and ultra-deep coalbed methane samples," China Petroleum Machinery, vol. 48, no. 1, pp. 40-45, 2020.

[14] W. Zhang, J. Liang, J. Lu et al., "Accumulation features and mechanisms of high saturation natural gas hydrate in Shenhu Area, northern South China Sea," Petroleum Exploration and Development, vol. 44, no. 5, pp. 670-680, 2017. 
[15] H. Qin, Research on Low-Disturbing Sampling Theory and Truth-Preserving Technique of Deep-Sea Surface Layer sediment, Zhejiang University, Hangzhou, China, 2005.

[16] C. C. Fu, B. J. Yang, B. S. Liu et al., "Optimization and application of coring technology in special formation of Bohai Oilfield," Drilling and Production Technology, vol. 42, no. 2, pp. 118-120, 2019.

[17] Hu Pan, K. ZHENG, and C. HE, "Research on design of gas coring tool for pressure-retaining and gas storage," Drilling and Production Technology, vol. 41, no. 2, pp. 89-90, 2018.

[18] K. A. Kvenvolden, L. A. Barnard, and D. H. Cameron, "Pressure core barrel: application to the study of gas hydrates, deep sea drilling project site 533," Drilling Project, vol. 76, pp. $367-375,1983$.

[19] A. V. Milkov, G. R. Dickens, G. E. Claypool et al., "Co-existence of gas hydrate, free gas, and brine within the regional gas hydrate stability zone at Hydrate Ridge (Oregon margin): evidence from prolonged degassing of a pressurized core," Earth \& Planetary Science Letters, vol. 222, no. 3-4, pp. 829-843, 2004.

[20] G. R. Dickens, P. J. Wallace, C. K. Paull, and W. S. Borowski, "Detection of methane gas hydrate in the pressure core sampler (PCS): volume-pressure-time relations during controlled degassing experiments,"vol. 164, pp. 113-126, in Proceedings of the Ocean Drilling Program: Scientific Results, vol. 164, Texas A\&M University, College Station, TX, USA, 2000.

[21] H. Amann, H. J. Hohnberg, and R. Reinelt, "HYACE-a novel autoclave coring equipment for systematic offshore gashydrate sampling Deutsche Wissenschaftliche Gesellschaft für Erdgas und Kohle e.V," Deutsche Wissenschaftliche Gesellschaft für Erdgas und Kohle eV (DGMK), vol. 9706, pp. 37-49, 1997.

[22] P. Schultheiss, M. Holland, and G. Humphrey, "Wireline coring and analysis under pressure: recent use and future developments of the HYACINTH system," Entific Drilling, vol. 7, no. 7, pp. 2809-2818, 2009.

[23] G. Bohrmann, W. F. Kuhs, S. A. Klapp et al., "Appearance and preservation of natural gas hydrate from Hydrate Ridge sampled during ODP Leg 204 drilling," Marine Geology, vol. 244, no. 1-4, pp. 1-14, 2007.

[24] K. U. Heeschen, M. Haeckel, H.-J. Hohnberg, F. Abegg, and G. Bohrmann, "Pressure coring at gas hydrate-bearing sites in the eastern Black Sea off Georgia," Geophysical Research Abstracts, vol. 9, 2007.

[25] R. Wakishima, "The development of a pressure temperature core sampler (PTCS) for the recovery of in-situ methane hydrate," in Proceedings of the International Symposium on Methane Hydrates, pp. 107-120, Chiba, Japan, 1998.

[26] H. W. Qin, L. L. Gu, S. L. Li, L. Zhu, and Y. Chen, "Pressure tight piston corer-a new approach on gas hydrate investigation," China Ocean Engineering, vol. 19, no. 1, pp. 121-128, 2005.

[27] D. Zhang, Z. Jiang, P. Yu et al., Thermal Insulation and Compression Core-Taking Drill for Shallow Holes in Deep Water of Natural Gas Hydrate, China Patent, CN 1818323A, 2006, in Chinese.

[28] H. Y. Zhu, Q. Y. Liu, G. R. Wong et al., "A pressure and temperature preservation system for gas-hydrate-bearing sediments sampler," Petroleum Science and Technology, vol. 31, no. 6, pp. 652-662, 2013.

[29] D. A. Hodgson, M. J. Bentley, J. A. Smith et al., "Technologies for retrieving sediment cores in Antarctic subglacial settings," Philosophical Transactions of the Royal Society A:
Mathematical, Physical and Engineering Sciences, vol. 374, no. 2059, p. 20150056, 2016.

[30] Y. Kubo, Y. Mizuguchi, F. Inagaki, and K. Yamamoto, "A new hybrid pressure-coring system for the drilling vessel," Scientific Drilling, vol. 17, no. 17, pp. 37-43, 2014.

[31] L. Yang, Y. Su, J. Luo, and S. Sun, "Development and application of GW-CP194-80A pressure-maintaining coring tool," Natural Gas Industry, vol. 40, no. 4, pp. 91-96, 2020.

[32] H. Ren, X. Pei, Z. Wu, G. Zhou, Q. Yang, and J. Xu, "Development and field tests of pressure-temperature preservation coring tools for gas hydrate," Petroleum Drilling Techniques, vol. 46, no. 3, pp. 44-48, 2018.

[33] J.-L. Xu and H. Ren, "Status of gas hydrate sampling technology and the research," Exploration Engineering (Rock \& Soil Drilling and Tunneling), vol. 39, no. 11, pp. 4-9, 2012.

[34] X. Zhang, J. Peng, M. Sun, Q. Gao, and D. Wu, "Development of applicable ice valves for ice-valve-based pressure corer employed in offshore pressure coring of gas hydrate-bearing sediments," Chemical Engineering Research and Design, vol. 111, pp. 117-126, 2016.

[35] D. Wu, J. Peng, M. Sun et al., "Experimental study on a pressure-coring technology based on a freeze-core valve for marine hydrate-bearing sediment sampling," Journal of Natural Gas Science and Engineering, vol. 33, pp. 135-142, 2016.

[36] H. Xie, "Research review of the state key research development program of China: deep rock mechanics and mining theory," Journal of China Coal Society, vol. 44, no. 5, pp. 1283-1305, 2019.

[37] Z. Q. He, L. Chen, T. Lu et al., "The optimization of pressure controller for deep earth drilling," Thermal Science, vol. 23, p. 123, 2019.

[38] M. Z. Gao, R. Zhang, J. Xie, G. Y. Peng, B. Yu, and P. G. Ranjith, "Field experiments on fracture evolution and correlations between connectivity and abutment pressure under top coal caving conditions," International Journal of Rock Mechanics and Mining Sciences, vol. 111, pp. 84-93, 2018.

[39] M. Gao, Z. Zhang, Y. Xiangang, C. Xu, Q. Liu, and H. Chen, "The location optimum and permeability-enhancing effect of a low-level shield rock roadway," Rock Mechanics and Rock Engineering, vol. 51, no. 9, pp. 2935-2948, 2018.

[40] F. Gong, J. Yan, S. Luo et al., "Investigation on the linear energy storage and dissipation laws of rock materials under uniaxial compression," Rock Mechanics and Rock Engineering, vol. 52, no. 12, pp. 4237-4255, 2019.

[41] Q. Cao, Research on the Facility for Producing Uinform Magnetic Field within Closed Ferromagnetic Boundaries, Harbin Institute of Technology, Harbin, China, 2018.

[42] W. Wang, F. Wang, B. Zhao, and G. Li, "Gas distribution law for the fully mechanized top-coal caving face in a gassy extrathick coal seam," Advances in Civil Engineering, vol. 2018, Article ID 3563728, 8 pages, 2018.

[43] W. Yu and F. Liu, "Stability of close chambers surrounding rock in deep and comprehensive control technology," Advances in Civil Engineering, vol. 2018, Article ID 6275941, 18 pages, 2018.

[44] H. Zhao, Y. Wang, and J. Tian, "Review of study on magnet machine and mechanism," Chinese Journal of Mechanical Engineering, vol. 39, no. 12, pp. 31-36, 2003.

[45] J. F. Bi, X. Q. Luo, and H. Shen, "Construction of uniform gradient magnetic field in geomechanics magnetic model 
test," Rock and Soil Mechanics, vol. 35, no. 1, pp. 257-263, 2014.

[46] C. Luo, K. Zhang, J. Duan et al., "Study of permanent magnet electrodynamic suspension system with a novel halbach array," Journal of Electrical Engineering \& Technology, vol. 2, no. 15, pp. 969-977, 2020.

[47] X. Wang, X. Li, C. Li et al., "Design of a PCB stator coreless axial flux permanent magnet synchronous motor based on a novel topology Halbach array," Frontiers of Information Technology \& Electronic Engineering, vol. 3, no. 20, pp. 414424, 2019. 